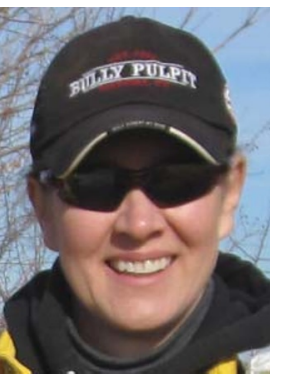

By Michelle Solga

\section{Buzzing the Literature}

This section is an invited contribution that reviews new publications available about pollinators. Copies of these publications can be obtained by contacting the respective publishers or senior authors (addresses shown in parentheses).

\section{Pollinator Decline}

Reconstruction of historical pollination rates reveals linked declines of pollinators and plants. A. Pauw and J. A. Hawkins. 2011. Oikos 120:344-349. (Dept of Botany and Zoology, Stellenbosch Univ, Private Bag X1, Matieland, 7602, South Africa.) Recent declines in pollinators have been associated with the concern over loss of pollination services, although specific evidence of pollination loss has been difficult to come by. In this research, a new method was devised to analyze present and historical plant-pollinator relationships using the oil-collecting bee Rediviva peringueyi and the oil-secreting orchid Pterygodium catholicum as study species. When historical pollination rates were compared to present rates, a decline in the pollination and abundance of this orchid was found.

Global pollinator declines: trends, impacts and drivers. S. G. Potts, J. C. Biesmeijer, C. Kremen, P. Neumann, O. Schweiger, and W. E. Kunin. 2010. Trends in Ecology and Evolution 25:345-353. (Centre for Agri-Environmental Research, School of Agriculture, Policy and Development, Univ of Reading, Reading RG6 6AR, UK.) A review highlighting the declining trend in pollinators, the potential causes of their decline, and the potential impact of pollinator decline on ecosystem services.

\section{Bee Conservation}

Translating research into action; bumblebee conservation as a case study. D. Goulson, P. Rayner, B. Dawson, and B. Darvill. 2011. Journal of Applied Ecology 48:3-8. (Bumblebee Conservation Trust, Univ of Stirling, Stirling FK9 4LA, UK.) Evidence of bumblebee declines in Europe, Asia, and North America warrant an increase in conservation efforts for this pollinator. In order for bumblebee conservation efforts to be successful, existing knowledge derived from research needs to be communicated to governmental policy makers, as well as land managers that implement on-the-ground conservation practices.

Forage use and niche partitioning by non-native bumblebees in New Zealand: implications for the conservation of their populations of origin. G. C. Lye, J. C. Kaden, K. J. Park, and D. Goulson. 2010. Journal of Insect Conservation 14:607-615. (School of Biological and Environmental Sciences, Univ of Stirling, Stirling, FK9 4LA, UK.) Four bumblebee species native to Britain were introduced into New Zealand starting in 1885, providing an opportunity to study these species from a conservation standpoint. Of these four species, one is extinct, two are declining, and one is considered common in Britain. In New Zealand these four species have an overlap in forage use, thought to be caused by the scarcity of diverse forage resources in the area. In Britain declining abundance of the preferred forage resources of these bumblebees is offered as a potential cause for their decline. 
The plight of the bees. M. Spivak, E. Mader, M. Vaughn, and N. H. Euliss, Jr. 2011. Environmental Science and Technology 45:34-38. (University of Minnesota, St. Paul, MN 55108, USA.) This review presents the contemporary causes for native and honey bee decline and potential solutions for mitigating this decline.

The montane bee fauna of north central Washington, USA, with floral associations. J. S. Wilson, L. E. Wilson, L. D. Loftis, and T. Griswold. 2010. Western North American Naturalist 70:198-207. (Dept of Biology, Utah State Univ, 5305 Old Main Hill, Logan, UT 84322-5305, USA.) The mountainous areas of north central Washington include habitats that range from shrub steppe to high-elevation alpine meadows, which are home to diverse assemblages of native bees and forbs.

The conservation and restoration of wild bees. R. Winfree. 2010. Annals of the New York Academy of Sciences Year in Ecology and Conservation Biology 2010, 1195:169-197. (Dept of Entomology, Rutgers Univ, New Brunswick, NJ 08901, USA.) This review discusses the economical and ecological contributions made by native bees, potential causes of native bee decline, and the importance of bee conservation.

\section{Habitat}

Floral and nesting resources, habitat structure, and fire influence bee distribution across an open-forest gradient. R. Grundel, R. P. Jean, K. J. Frohnapple, G. A. Glowacki, P. E. Scott, and N. B. Pavlovic. 2010. Ecological Applications 20:1678-1692. (US Geological Survey, Great Lakes Science Center, 1100 North Mineral Springs Road, Porter, IN 46304, USA.) Native bee communities responded positively to environmental factors such as plant diversity, resources for nesting, and fire history and negatively to forest canopy cover.

Bee communities (Hymenoptera: Apoidea) of small Iowa hill prairies are as diverse and rich as those of large prairie preserves. S. D. Hendrix, K. S. Kwaiser, and S. B. Heard. 2010. Biodiversity and Conservation 19:1699-1709. (Dept of Biological Sciences, Univ of Iowa, 134 Biology Building, Iowa City, IA 52242-1324, USA.) Small hill prairie remnants in northeast Iowa can provide floral resources for native bees; however, their visitation may be influenced by surrounding landscape features such as agricultural row crops and open water.

How many flowering plants are pollinated by animals? J. Ollerton, R. Winfree, and S. Tarrant. 2011. Oikos 120: 321-326. (School of Science and Technology, Univ of Northampton, Avenue Campus, Northampton, NN2 6JD, UK.) Pollination is important in providing increased genetic diversity to plants, as some plants are unable to reproduce or set their seed without this vital service. This study uses 42 published and unpublished surveys to compile a community-level comprehensive data set of animal pollinated plants.

Reproduction of Echinacea angustifolia in fragmented prairie is pollen-limited but not pollinator-limited. $S$. Wagenius and S. P. Lyon. 2010. Ecology 91:733-742. (Div of Plant Biology and Conservation, Chicago Botanic Garden, 1000 Lake Cook Road, Glencoe, IL 60022, USA.) Echinacea angustifolia, a native tallgrass prairie forb, is common in small prairie remnants of the Midwest. Pollinator visitation was greater in isolated plants, but reproduction of E. angustifolia under these circumstances did not increase.

\section{Environmental Disturbance}

The effect of invasive Lythrum salicaria pollen deposition on seed set in the native species Decodon verticillatus. E. M. DaSilva and R. D. Sargent. 2011. Botany 89:141-146. (Dept of Biology, Univ of Ottawa, 30 Marie-Curie Street [160 Gendron Hall], Ottawa, ON K1N 6N5, Canada.) Invasive plants have the potential to compete with native plant species for pollinators ultimately affecting the native plant's fitness. In a glasshouse experiment, native loosestrife Decodon verticillatus showed a decrease in seed set when hand pollinated with a mixture of conspecific and heterospecific pollen from the invasive wetland plant Lythrum salicaria when compared to pollination with conspecific pollen alone.

Ecological and life-history traits predict bee species responses to environmental disturbances. N. M. Williams, E. E. Crone, T. H. Roulston, R. L. Minckley, L. Packer, and S. G. Potts. 2010. Biological Conservation 143:2280-2291. (Dept of Entomology, Univ of California, One Shields Ave, Davis, CA 96616, USA.) A global analysis of 19 studies determined that life history and ecological traits can influence the response of bees to anthropogenic disturbances. These results in turn aid land managers and stakeholders in future land use decisions.

\section{Ecosystem Restoration}

Reconnecting plants and pollinators: challenges in the restoration of pollination mutualisms. M. H. M. Menz, R. D. Phillips, R. Winfree, C. Kremen, M. A. Aizen, S. D. Johnson, and K. W. Dixon. 2011. Trends in Plant Science 16:4-12. (Botanic Gardens and Parks Authority, King's Park and Botanic Garden, Fraser Ave, West Perth 6005, Australia.) Plant-pollinator interactions should be considered in restorations of degraded ecosystems. Restoration ecologists and pollination biologists need to work in tandem to ensure a sustainable habitat is provided that will benefit native pollinators.

\section{Management Factors}

Impacts of a pesticide on pollinator species richness at different spatial scales. C. A. Brittain, M. Vighi, R. Bommarco, J. Settele, and S. G. Potts. 2010. Basic and Applied Ecology 
11:106-115. (Centre for Agri-Environmental Research, Univ of Reading, Reading RG6 6AR, UK.) Effects of the insecticide fenitrothion in vine fields in Italy was investigated for its effect on wild pollinators. Cultivated and uncultivated systems were compared, and pollinators were sampled at three spatial scales. Wild bees, as compared to bumblebees or butterflies, showed particular sensitivity to the effects of this insecticide.

Management tradeoffs between focal species and biodiversity: endemic plant conservation and solitary bee extinction. P. M. Severns and A. R. Moldenke. 2010. Biodiversity and Conservation 19:3605-3609. (Dept of Botany and Plant Pathology, Oregon State Univ, Corvallis, OR
97331, USA.) Land management choices can have implications to biodiversity of a habitat that are unintended. Management that promoted eradication of one species to promote endemic plant conservation had negative consequences on a rare solitary bee that was dependent on the eradicated floral resource. Management practices should be evaluated for unintended consequences that can have negative impacts on the biodiversity of an area.

Author is a Graduate Research Assistant, Range Science Program, School of Natural Resource Sciences, North Dakota State University, Fargo, ND 58105, USA. 